\title{
ANÁLISE POR MÚLTIPLOS CRITÉRIOS PARA A DEFINIÇÃO DE NÍVEIS DE FRAGILIDADE AMBIENTAL - UM ESTUDO DE CASO: BACIA HIDROGRÁFICA DO RIO CARÁ-CARÁ, PONTA GROSSA/PR
}

\author{
Analysis by multiple criteria for the \\ definition of environmental fragility levels - \\ A case study: watershed of \\ Cará-Cará River, Ponta Grossa/PR
}

Marcos Antonio MIARA ${ }^{1}$

Chisato OKA-FIORI ${ }^{2}$

\section{RESUMO}

Os SIGs (Sistemas de Informações Geográficas) como ferramentas de análise ambiental a partir de módulos específicos possibilitam utilizar diversas informações concomitantemente. A fim de explorar tal capacidade, a presente pesquisa aplicou uma Avaliação por Múltiplos Critérios (MCE), utilizando também o método AHP (Analytic Hierarchy Process) para a identificação de níveis diferenciados de fragilidade ambiental a partir da definição de pesos às variáveis físicas consideradas. O trabalho utilizou a bacia hidrográfica do rio Cará-Cará, Ponta Grossa/PR, como área de estudo. Os resultados demonstraram uma variação de cinco classes de fragilidade ambiental que se correlacionaram com a realidade, fornecendo assim subsídios para uma avaliação positiva dos métodos utilizados.

Palavras-chave:

Análise por Múltiplos Critérios; fragilidade ambiental; bacia hidrográfica do rio Cará-Cará.

\begin{abstract}
The GIS (Geographical Information Systems), as a tool for the environmental analyses of specific modules, makes possible the use of different sources of information simultaneously. In order to exploit this characteristic, the present research applied a Multi criteria evaluation (MCE), using also the AHP (Analytic Hierarchy Process) for the identification of differentiated levels of environmental fragility from the definition of weights for the considered physical variables. The work has used the CaráCará River watershed, Ponta Grossa/PR, as its study area. The results have shown a five-class variation of environmental fragility, which have been correlated witch the reality, giving support to a positive evaluation of the methods which were used.
\end{abstract}

\section{Key words:}

Multi-Criteria Evaluation; environmental fragility; watershed of Cará-Cará river.

\footnotetext{
1 Mestre em Geografia pela UFPR.

2 Professora adjunta doutora do Departamento de Geografia da UFPR.
} 
MIARA, M. A.; OKA-FIORI, C. Análise por múltiplos critérios para a definição de níveis de fragilidade ambiental...

\section{INTRODUÇÃO}

Todo ambiente formado por seu conjunto de condicionantes físicas apresenta respostas únicas às atividades humanas que dele se apropriam. Essa condição representa as diferentes composições de cada porção de globo, assim como as suas diferentes condições de fragilidade. Assim, conforme as combinações das características ambientais de um dado local, maior ou menor será sua vulnerabilidade frente às ações antrópicas.

Porém, para a definição dos diferentes níveis de fragilidade de um espaço qualquer considerando seus variados componentes físicos, é necessário conjugar dentro de uma análise os respectivos valores e as importâncias de cada variável com relação à fragilidade ambiental. $\mathrm{O}$ primeiro obstáculo para essa tarefa é com relação à forma de se trabalhar com um grande número de informações, processá-las, e delas extrair um determinado resultado. $\mathrm{O}$ segundo é estabelecer uma relação de importância entre as variáveis que mais se assemelhe com a realidade.

Assim, o presente estudo demonstra uma proposta que procura transpor tais obstáculos, realizando uma análise de níveis diferenciados de fragilidade ambiental da bacia hidrográfica do rio Cará-Cará (BHCC), seguindo alguns preceitos metodológicos de Ross (1990; 1994; 1995). A pesquisa considerou como componentes físicos a geologia da área, os tipos de solos, as formas predominantes de vertentes, a declividade e o potencial erosivo da chuva. As informações cartográficas foram processadas a partir da implantação de um SIG, sendo utilizados os softwares Spring V.4.1.1 e Idrisi V.I32.2 a partir de uma análise por múltiplos critérios através de uma avaliação hierárquica entre as variáveis ambientais utilizadas na pesquisa.

\section{CARACTERIZAÇÃO FíSICA DA ÁREA DE ESTUDO}

A bacia hidrográfica do rio Cará-Cará (BHCC) se localiza no município de Ponta Grossa/PR, possui uma área de $102,18 \mathrm{~km}^{2}$ e faz parte da bacia hidrográfica do rio Tibagi. Localiza-se na parte central do município, abrangendo a parte leste e sudeste do perímetro urbano da cidade e parte da área rural do município. Localiza-se entre as coordenadas UTM $584.634 \mathrm{~m}$ e $597.960 \mathrm{~m}$ em $\mathrm{X}$, e $7.214 .090 \mathrm{~m}$ e $7.225 .298 \mathrm{~m}$ em Y (Figura 1).

ABHCC possui altitudes que variam de 779 a 1.027 metros, sendo que as maiores altitudes encontram-se na parte leste da bacia e diminuem no sentido oeste e sul, para onde correm os principais canais. Seus topos são aplainados e seus divisores estendem-se nos sentidos leste/oeste, norte/sul e nordeste/sudoeste, dando um formato triangular à bacia. Em sua maior parte, a bacia apresenta baixas declividades, as quais aumentam sem grandes variações sentido encostas abaixo. As maiores declividades associam-se principalmente às rupturas do relevo influenciadas por intrusões de diques e soleiras de Diabásio e por falhas e linhas de fratura. Sobre as vertentes, as formas côncavas possuem maior área e ocorrem principalmente na porção nordeste da bacia. As vertentes convexas são o tipo de segunda maior expressão em área e ocorrem nas porções centrais e leste da bacia. As vertentes retilíneas distribuem-se em especial na parte sul da bacia e associam-se também às rupturas do relevo. As planícies localizam-se na porção sul e se estendem até cota de 800 metros.

O substrato geológico é composto principalmente pela Formação Furnas, que é formada por sedimentos depositados em ambiente aluvial e litorâneo, constituída por arenitos médios a grosseiros com estratificações

\section{FIGURA 1 - LOCALIZAÇÃO DA ÁREA DE ESTUDO}

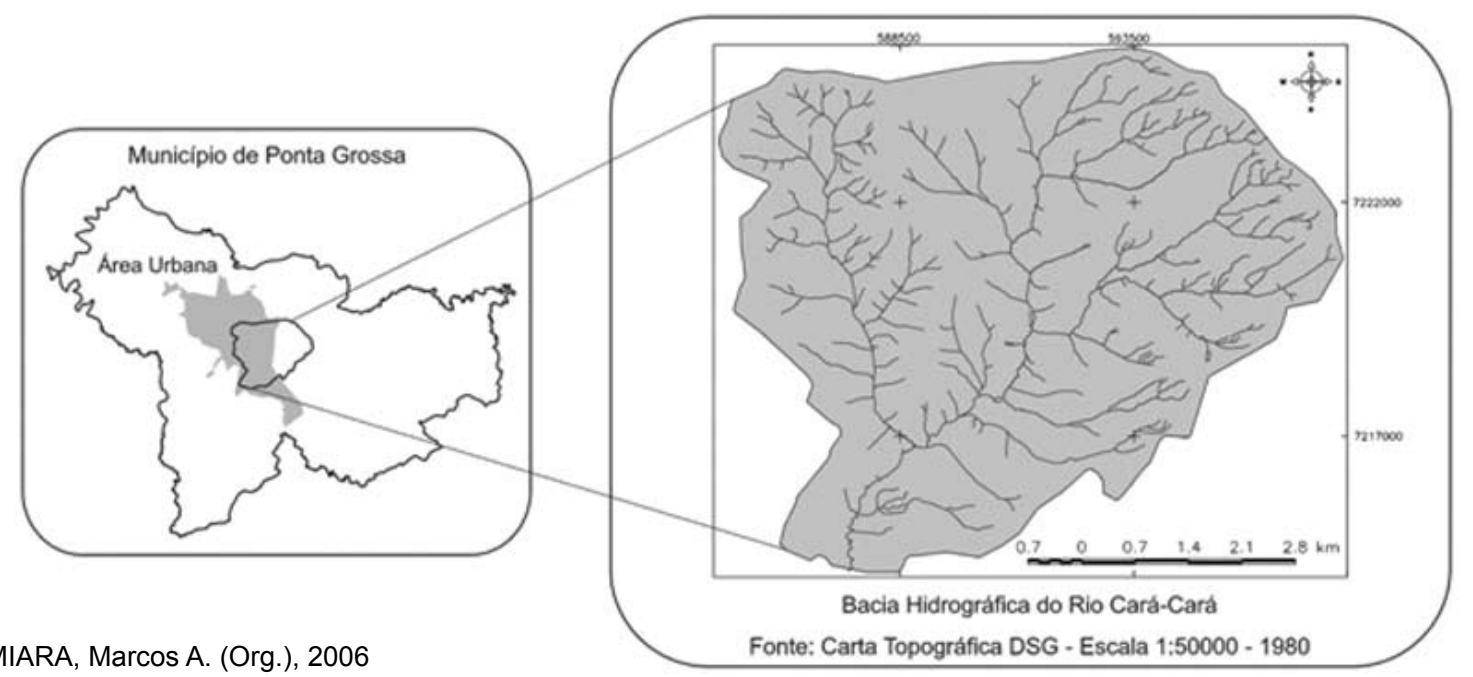

FONTE: MIARA, Marcos A. (Org.), 2006

R. RA'E GA, Curitiba, n. 13, p. 85-98, 2007. Editora UFPR 
MIARA, M. A.; OKA-FIORI, C. Análise por múltiplos critérios para a definição de níveis de fragilidade ambiental...

cruzada e horizontal (MINEROPAR, 2001). Ocorre também a Formação Ponta Grossa, oriunda de depósitos litorâneos e de plataforma, formada por folhelhos e siltitos cinzentos, localmente betuminosos com intercalações de arenitos muito finos (MINEROPAR, 2001). Ocorrem ainda diques e soleiras de Diabásio da Formação Serra Geral e depósitos quaternários na foz do rio Cará-Cará.

Quanto aos solos da BHCC, foram identificados, de acordo com o mapeamento utilizado, cinco tipos. Os Latossolos ocupam a maior parte da área, distribuindose por $72,1 \%$ da bacia. O Latossolo 'LEa8' ocupa a porção central da bacia e apresenta um relevo plano a suave ondulado. O Latossolo 'LEa9' se assemelha ao tipo anterior com relação ao relevo e encontra-se quase que totalmente sobrepondo litologias da Formação Furnas. A associação Latossolo e Podzólico 'LEa14' apresenta mais de $65 \%$ de sua área sobre a Formação Furnas. Mais de $58 \%$ da área deste solo apresentam declividades entre 0 e $6 \%$, e cerca de $34 \%$ de sua área apresenta-se com declividades entre 6 e $12 \%$.

O solo 'Ca23' que representa uma associação entre Cambissolo e Podzólico ocupa cerca de $25 \%$ da BHCC. Distribui-se principalmente nas cabeceiras do arroio Olarias e pelo vale do mesmo. Essa classe apresenta as maiores variações de declividade, onde cerca de $15 \%$ de sua totalidade de área apresenta declives entre 12 e $20 \%$, e $5 \%$ de sua área com declives de 20 a $30 \%$. Quanto ao substrato geológico, em torno de $74 \%$ desse solo sobrepõe a Formação Ponta Grossa. A classe 'HG2' sobrepõe totalmente os depósitos Quaternários e possui um relevo praticamente plano.

A cobertura vegetal original da bacia segue as descrições do Segundo Planalto Paranaense, definido como a região fitogeográfica dos Campos Gerais, onde a maior parte do município de Ponta Grossa se insere. É caracterizada pela predominância de campos limpos, com a presença de gramíneas, arbustos e semiarbustos, ocorrendo também matas ou capões e matas de galeria. Possui elementos da Savana estépica gramíneo-lenhosa interpolada pela Floresta Ombrófila Mista (LEITE e KLEIN, 1990, citados por MORO, 2001) tendo, porém, uma cobertura predominantemente herbácea, com elementos arbustivos lenhosos, apresentando um aspecto fisionômico típico (KLEIN e HATSCHBACH, 1971, citados por MORO e KACZMARECH, 2001).

O clima da região é, segundo $W$. Koeppen, Cfb sempre úmido, com clima quente-temperado, com o mês mais quente com temperaturas médias abaixo de $22^{\circ} \mathrm{C}$, com onze meses com temperatura média acima de $10^{\circ} \mathrm{C}$, e mais de cinco geadas noturnas por ano. Os dados meteorológicos do Instituto Tecnológico SIMEPAR relativos aos anos de 1998 a 2003 registraram uma temperatura média de $18,1^{\circ} \mathrm{C}$, sendo o mês mais quente (março de 2002) com uma temperatura média de $22,6^{\circ} \mathrm{C}$, e o mês mais frio (julho de 2000) com uma temperatura média de $11,4^{\circ} \mathrm{C}$.A precipitação média anual entre os períodos de 1945 e 2004 , de acordo com dados fornecidos pela Superintendência de Desenvolvimento de Recursos Hídricos e Saneamento Ambiental (SUDERHSA), foi de $1.515,4 \mathrm{~mm}$, com a média de 110,8 dias de chuva por ano. Os meses onde a precipitação média foi maior foram janeiro $(171,3 \mathrm{~mm})$ e fevereiro (161,9 mm), e os meses com menores precipitações médias foram agosto (75,3 mm), abril (92,1 mm) e julho (98,4 mm). O mês que registrou a maior precipitação foi março de 1998, com 497,8 mm, e o mês de menor precipitação foi junho de 1948, com precipitação de 0,0 mm.

\section{MATERIAL E MÉTODOS}

\section{MATERIAL}

Os materiais utilizados referem-se às fontes cartográficas utilizadas, às informações climáticas e aos softwares empregados para a realização da pesquisa, os quais são:

- Carta Topográfica de 1980, Folha Ponta Grossa SG. 22-X-C-II / 2 (Ml - 2840/2), em escala 1:50.000 da Diretoria de Serviço Geográfico (DSG, 1980);

- Carta Geológica do mapeamento do Projeto Leste do Paraná, Folha Ponta Grossa SG-22-X-C-II-2, em escala 1:50.000 (AGUIAR NETO, 1977);

- Mapeamento Geológico do Município de Ponta Grossa, em escala 1:250.000 (GODOY, 200?);

- Levantamento de Reconhecimento dos Solos do Estado do Paraná, em escala 1:600.000, organizado por Higa (2003) para o SIFLOR Sistema de Informações para Planejamento Florestal;

- dados meteorológicos da Estação Ponta Grossa fornecidos pelo Instituto Tecnológico SIMEPAR, referentes aos anos de 1960 a 2004;

- dados meteorológicos da Estação Santa Cruz fornecidos pela Superintendência de Desenvolvimento de Recursos Hídricos e Saneamento Ambiental (SUDERHSA), referentes aos anos de 1960 a 2004; 
MIARA, M. A.; OKA-FIORI, C. Análise por múltiplos critérios para a definição de níveis de fragilidade ambiental...

- dados meteorológicos da Fazenda Escola Capão da Onça, fornecidos pela Universidade Estadual de Ponta Grossa, referentes aos anos de 1999 a 2004;

- softwares de geoprocessamento Spring V.4.1.1 e Idrisi V.I32.2;

- software Excel para a edição das planilhas dos dados meteorológicos.

\section{MÉTODOS}

\section{FORMAÇÃO DA BASE DE DADOS CARTOGRÁFICOS}

Essa etapa da pesquisa foi composta pela digitalização dos dados cartográficos utilizados na análise e pela adequação dos arquivos para os procedimentos posteriores. Para tanto, as cartas foram transferidas para o formato digital e geo-referenciadas utilizando-se o software Spring V.4.1.1. O passo seguinte foi fazer a digitalização dos dados cartográficos que seriam usados.

Foram transferidas para formato vetorial a rede hidrográfica, os pontos cotados e as curvas de nível para a delimitação da área da bacia. Ainda a partir dos dados altimétricos, foi produzida a carta de declividades. Pelos mapeamentos de solos e de geologia utilizados como fonte, foram digitalizadas as diferentes classes ocorrentes na bacia através da representação poligonal associadas às respectivas classes temáticas. Pela análise empírica das curvas de nível foram aglutinados, também através de polígonos associados a classes temáticas, os tipos predominantes de formas de vertentes.

As estações pluviométricas foram pontuadas por suas coordenadas. A cada ponto foi dado o seu respectivo valor de potencial erosivo da chuva, o fator 'El'. Esse fator é um índice numérico que expressa a potencialidade da chuva de causar erosão em uma área que não possui proteção do solo (BERTONI e LOMBARDI NETO, 1990). É calculado de diferentes formas e, para esta pesquisa, foi considerado o trabalho de Lombardi Neto e Moldenhauer (1980), citados por Bertoni e Lombardi Neto (1990), que para a região de Campinas/SP encontraram grande correlação para a regressão linear entre o índice médio mensal de erosão e o coeficiente da chuva em 22 anos de análise. A relação proposta por esses autores é a que segue:
Onde:

$\mathrm{El}=$ Erosividade média mensal da chuva expressa em MJ.mm/ha.L

$\mathrm{p}=$ Precipitação média mensal em 'mm';

$\mathrm{P}=$ Precipitação média anual em 'mm'.

Para obter o índice de erosividade médio anual 'R', é realizada a soma das médias mensais através da fórmula:

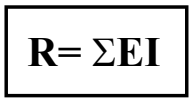

$$
E I=67,355\left(p^{2} / P\right)^{0,85}
$$

Os valores de 'El' de cada estação pluviométrica foram interpolados a partir de uma grade retangular utilizando-se o método de média ponderada, onde o valor de cota de cada ponto da grade é calculado a partir da média ponderada das cotas dos ' 8 ' vizinhos mais próximos a esse ponto. Porém, atribuem-se pesos variados para cada ponto amostrado através de uma função que considera a distância do ponto cotado ao ponto da grade. Esse interpolador produz resultados intermediários entre o interpolador de média simples e outros interpoladores mais sofisticados, com tempo de processamento menor (INPE, 2005).

Após a conclusão da grade retangular, e utilizando-se do mesmo software, foi produzida uma carta de isoerodentes, e posteriormente foi realizado o fatiamento dessa carta para a variação de intervalos utilizados neste trabalho.

Esses dados seguiram uma padronização quanto aos seus retângulos envolventes, escalas e resoluções espaciais, assim como todos os dados em formato vetorial foram transformados em formato matricial para as etapas que viriam a seguir. Os resultados até então são as cartas de declividade, de solos, de geologia, de tipos predominantes de formas de vertentes e de erosividade da chuva da BHCC.

\section{CLASSIFICAÇÕES DE IMPORTÂNCIA DAS VARIÁVEIS}

Nessa fase da pesquisa, as classes de cada variável foram dispostas, conforme a bibliografia consultada e as práticas de campo, em uma seqüência de influências ao desenvolvimento de processos erosivos. (Quadro 1) 
MIARA, M. A.; OKA-FIORI, C. Análise por múltiplos critérios para a definição de níveis de fragilidade ambiental...

As sete classes de declividade foram dispostas de forma crescente, já que quanto maiores são as inclinações maior será a energia empregada ao escoamento superficial. Para a hierarquização dos tipos de solos, foi utilizada a descrição de Ross (1994) quanto às classes de fragilidade. Foram consideradas também as descrições de Larach et al. (1984) e de Higa (2003).

Para a geologia, foi considerada a descrição da escala de vulnerabilidade das litologias à denudação proposta por Crepani et al. (2001). Foi considerada também a densidade de linhas de fratura presentes sobre cada unidade litológica extraídas pelo alinhamento da drenagem (SOARES e FIORI, 1976), assim como as densidades de drenagem e hidrográfica e a extensão do percurso superficial (EPS) sobre as litologias. Esses parâmetros demonstraram índices diferenciados de rugosidade topográfica, principalmente entre as Formações Ponta Grossa e Furnas, e ajudaram na definição da hierarquia da geologia para a bacia.

Sobre as vertentes, há que se considerar que cada forma influencia de modo particular o processo de escoamento superficial e de formas de concentração das águas pluviais, proporcionando assim dinâmicas próprias a cada vertente no que se refere a erosão e a deposição de materiais.

\begin{tabular}{|c|c|c|c|c|c|c|c|c|}
\hline CATEGORIA & VALOR & DECLIVIDADE & CATEGORIA & VALOR & SOLOS & GEOLOGIA & VERTENTES & EROSIVIDADE \\
\hline $\begin{array}{l}\text { Extremamente } \\
\text { Fraca }\end{array}$ & 1 & 0 a $2 \%$ & Muito Baixo & 1 & LEa8 & $\begin{array}{l}\text { Formação } \\
\text { Serra Geral }\end{array}$ & Planícies & $\begin{array}{l}6.000 \text { a } 7.000 \\
\text { MJ.mm / ha.L }\end{array}$ \\
\hline Muito Fraca & 2 & 2 a $6 \%$ & Baixo & 2 & LEa9 & $\begin{array}{c}\text { Formação } \\
\text { Ponta } \\
\text { Grossa }\end{array}$ & Convexas & $\begin{array}{c}\text { Maior que } 7.000 \\
\text { MJ.mm / ha.L }\end{array}$ \\
\hline Fraca & 3 & 6 a $12 \%$ & Intermediário & 3 & LEa14 & $\begin{array}{c}\text { Formação } \\
\text { Furnas }\end{array}$ & Retilíneas & \\
\hline Média & 4 & 12 a $20 \%$ & Alto & 4 & Ca23 & $\begin{array}{l}\text { Depósitos } \\
\text { Quater- } \\
\text { nários }\end{array}$ & Côncavas & \\
\hline Forte & 5 & 20 a $30 \%$ & Alto & 4 & HG2 & & & \\
\hline Muito Forte & 6 & 30 a $45 \%$ & & & & & & \\
\hline $\begin{array}{l}\text { Extremamente } \\
\text { Forte }\end{array}$ & 7 & Maior que $45 \%$ & & & & & & \\
\hline
\end{tabular}

\section{QUADRO 1 - CLASSES HIERÁRQUICAS PARA CADA VARIÁVEL}

As vertentes convexas são para Boiko e Santos (2004) formas de relevo propensas à infiltração moderada com escoamento superficial e fluxo hídrico disperso, onde processos de erosão linear, deslizamentos, escorregamentos, rastejamentos (Creep) e escoamento difuso (rill wash) podem ocorrer. Para Penteado (1980), nas vertentes convexas a erosão linear é maior que a areolar, ocorrendo o recuo e a suavização dos declives mais lentos. Quanto mais os declives aumentam, maiores serão as quantidades de material transportado, já que as superfícies convexas são controladas por rastejamento e escoamento difuso que esculpem o topo convexo.

Sobre as vertentes retilíneas, ainda segundo Penteado (1980), os processos erosivos, quando ocorrem, são muito rápidos, aparecendo gargantas após tempestades, solapamento de base pelos rios e rastejamento de solo nos topos. Rodrigues (1998) complementa que, nessas vertentes, quando há um manto de intemperismo profundo, normalmente ocorre escoamento laminar superficial e sub-superficial, e a intervenção antrópica nessas vertentes pode gerar processos erosivos como sulcos, transporte de materiais e deposição nas bases da vertente.
Nas vertentes côncavas, há convergência do fluxo hídrico que corre no seguimento côncavo da vertente, onde a infiltração é menor que o escoamento superficial, o que faz com que esta se concentre. A denudação apresenta-se ativa, levando a processos de ravinamento, produção de sulcos e voçorocas, que podem ser formados por meio de lavagem em lençol, lavagem pluvial (rain wash) ou escoamento linear (sheet wash). (BOIKO e SANTOS, 2004)

\section{REESCALONAMENTO DAS VARIÁVEIS - PADRONIZAÇÃO FUZZY}

Essa etapa consistiu na utilização do módulo Fuzzy do software Idrisi V.I32.2 para fazer um reescalonamento das classes citadas no item anterior. A Função Fuzzy avalia a possibilidade que cada pixel pertença a um conjunto de alguma avaliação de uma série de funções. Possuem as funções Sigmoidal, J-Shaped e Linear, que são controladas por quatro pontos ordenados de baixo para cima em uma escala mensurável. O primeiro ponto marca o lugar onde a função começa a 
MIARA, M. A.; OKA-FIORI, C. Análise por múltiplos critérios para a definição de níveis de fragilidade ambiental...

elevar-se a partir de ' 0 '. O segundo ponto indica onde ele atinge ' 1 ', ou '255', conforme a escolha do usuário. O terceiro ponto indica o lugar onde gradativamente começa a descer novamente abaixo de ' 1 ' ou '255', enquanto o quarto ponto marca onde ele retorna ao ' 0 ' (zero). Pontos podem ser duplicados para criar funções monótonas ou lineares. O uso da função requer a entrada de pontos de controle e seus correspondentes valores, e estes servem para definir a modelagem da curva gráfica. A saída pode ser escalonada de '0 a 1' ou de '0 a 255' (EASTMAN, 1995).

Para cada uma das imagens, foi utilizada uma determinada função com seus respectivos pontos de inflexão. Para os mapas de Solos, Geologia e de Tipos Predominantes de Vertentes, foram utilizados pontos de inflexão '0 e 4' com função Linear (Quadro 2 e Figura 2). Para o mapa de Erosividade da Chuva, foram utilizados

\begin{tabular}{|cc|}
\hline $\begin{array}{c}\text { CLASSES DE SOLOS, } \\
\text { GEOLOGIA E VERTENTES }\end{array}$ & $\begin{array}{c}\text { VALORES A PARTIR DA } \\
\text { FUNÇÃO FUZZY }\end{array}$ \\
\hline 1 & 64 \\
2 & 128 \\
3 & 191 \\
4 & 255 \\
\hline
\end{tabular}

\section{QUADRO 2 - PADRONIZAÇÃO FUZZY - VARIÁVEIS: SOLOS, GEOLOGIA E VERTENTES}

\begin{tabular}{|cc|}
\hline $\begin{array}{c}\text { CLASSES DE EROSIVIDADE } \\
\text { DA CHUVA }\end{array}$ & $\begin{array}{l}\text { VALORES A PARTIR } \\
\text { DA FUNÇÃO FUZZY }\end{array}$ \\
\hline 1 & 128 \\
2 & 255 \\
\hline
\end{tabular}

\section{QUADRO 3 - PADRONIZAÇÃO FUZZY - VARIÁVEL: POTENCIAL EROSIVO DA CHUVA}

pontos de inflexão '0 e 2' também com função Linear (Quadro 3 e Figura 3). Para o mapa de Declividades, foram utilizados pontos de inflexão ' 5 e 7 ' e a função J-Shaped (Quadro 4 e Figura 4).

A diferença de função para o mapa de Declividades se deu por ser considerado que as classes que apresentam baixas declividades exercem pouca influência à erosão, assim como é considerado que as declividades maiores são de influência muito maior a processos erosivos. Assim, foi dada maior relevância a essa diferença entre as classes de declividade, não seguindo uma linearidade como nos outros critérios.

O resultado desse procedimento foi a obtenção de 6 (seis) mapas correspondentes aos dados analisados, nos quais todas as suas classes foram dispostas em uma mesma escala de valores, ou seja, em uma escala que varia de ' 0 a 255 '.

\section{FIGURA 2 - GRÁFICO PADRONIZAÇÃO FUZZY - VARIÁVEIS: SOLOS, GEOLOGIA E VERTENTES}

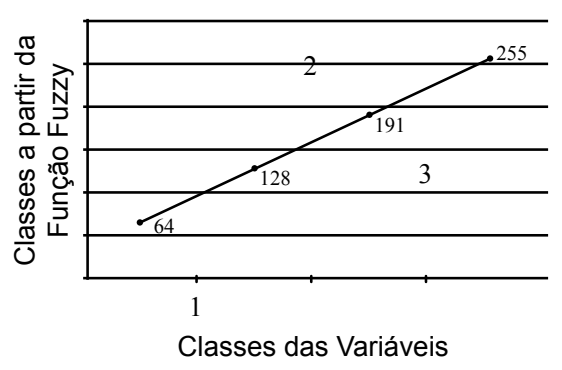

\section{FIGURA 3 - GRÁFICO PADRONIZAÇÃO FUZZY - VARIÁVEL: POTENCIAL EROSIVO DA}

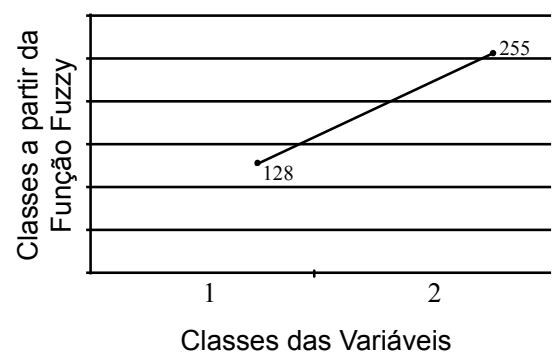


MIARA, M. A.; OKA-FIORI, C. Análise por múltiplos critérios para a definição de níveis de fragilidade ambiental...

\begin{tabular}{|cc|}
\hline $\begin{array}{c}\text { CLASSES DE } \\
\text { DECLIVIDADES }\end{array}$ & $\begin{array}{l}\text { VALORES A PARTIR } \\
\text { DA FUNÇÃO FUZZY }\end{array}$ \\
\hline 1 & 26 \\
2 & 35 \\
3 & 51 \\
4 & 78 \\
5 & 128 \\
6 & 204 \\
7 & 255 \\
\hline
\end{tabular}

\section{QUADRO 4 - PADRONIZAÇÃO FUZZY - VARIÁVEL: DECLIVIDADE}

\section{ANÁLISE PONDERADA DAS VARIÁVEIS}

Essa etapa teve como função aplicar à análise uma ponderação dos valores de cada variável utilizada. Para tanto, foi estabelecida uma relação de importância entre cada variável e todas as demais tentando definir o quanto cada elemento era mais importante que os outros. É de entendimento do autor que essa tarefa é impossível de ser exata quando se concebe o ambiente como um sistema aberto e dinâmico, carregando assim uma carga indissociável de subjetividade. Esse procedimento por outro lado, os autores também crêem em uma possibilidade maior de correlação com a realidade quando se considera essa relação ponderada entre as variáveis, no lugar de criar uma matriz algébrica entre os valores definidos para cada classe de cada variável. Isso se dá pela possibilidade de considerar as peculiaridades de cada espaço dentro de um estudo, valorando ou mais ou menos alguns diferentes aspectos desse espaço.

Zambon et al. (2005) descrevem que o método que foi aplicado nessa etapa é o de comparação 'par a par' no contexto do processo de tomada de decisão,

\section{FIGURA 4 - GRÁFICO PADRONIZAÇÃO FUZZY - VARIÁVEL: DECLIVIDADE}

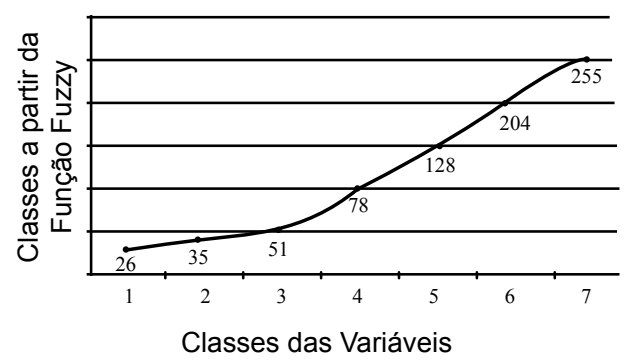

que é denominado também de AHP (Analytic Hierarchy Process). Thomas Saaty, em 1977, propôs uma técnica de escolha baseada na lógica da comparação pareada. Nesse procedimento, os diferentes fatores que influenciam a tomada de decisão são comparados 'doisa-dois', e um critério de importância relativa é atribuído ao relacionamento entre esses fatores, conforme uma escala predefinida (INPE, 2005).

Essa técnica baseia-se numa matriz quadrada ' $n \times n$ ', onde as linhas e colunas correspondem aos critérios analisados para o problema em questão. Assim, o valor de cada célula da matriz representa a importância relativa do critério da linha face ao critério da coluna. Como essa matriz é recíproca, apenas a metade triangular inferior necessita ser avaliada, já que a outra metade deriva desta, e a diagonal principal assume valores iguais a '1' (ZAMBON et al., 2005). O estabelecimento de comparações 'par a par' para todos os critérios precisa da definição de uma escala destinada à normalização. No Quadro 5 é apresentada a escala proposta por INPE (2005).

Para a BHCC, a escala de importância relativa

\begin{tabular}{cr}
$\begin{array}{c}\text { INTENSIDADE DE } \\
\text { IMPORTÂNCIA }\end{array}$ & DEFINIÇÃO E EXPLICAÇÃO \\
\hline 1 & Importância igual - os dois fatores contribuem igualmente para o objetivo \\
3 & Importância moderada - um fator é ligeiramente mais importante que o outro \\
5 & Importância essencial - um fator é claramente mais importante que o outro \\
7 & Importância demonstrada - um fator é fortemente favorecido e sua maior relevância \\
9 & foi demonstrada na prática \\
$2,4,6,8$ & Valores intermediários entre julgamentos - possibilidade de compromissos adicionais \\
\hline
\end{tabular}

QUADRO 5 - ESCALA DE VALORES AHP PARA COMPARAÇÃO PAREADA

FONTE: INPE (2005) 
MIARA, M. A.; OKA-FIORI, C. Análise por múltiplos critérios para a definição de níveis de fragilidade ambiental...

utilizada entre os fatores está demonstrada no Quadro 6.

\begin{tabular}{|cccccc|}
\hline & EROSIVIDADE & GEOLOGIA & VERTENTES & SOLOS & DECLIVIDADE \\
\hline Erosividade & 1 & & & & \\
& - & - & - & - & \\
Geologia & 2,8 & 1 & - & - & - \\
Vertentes & 3,6 & 1,28 & 1 & - & - \\
Solos & 4,6 & 1,64 & 1,27 & 1 & - \\
Declividade & 8 & 2,85 & 2,22 & 1,74 & 1 \\
\hline
\end{tabular}

\section{QUADRO 6 - ESCALA RELATIVA DE IMPORTÂNCIA ENTRE AS VARIÁVEIS FÍSICAS DA BHCC}

Para esse procedimento, foi utilizado o módulo WHEIGHT do software Idrisi 32 V.I32.01, que utiliza a técnica de comparação pareada para desenvolver um conjunto de pesos de fatores. As comparações referemse à importância relativa de dois fatores a cada avaliação na determinação de sua aptidão para um objetivo determinado. O módulo informa os novos pesos juntamente com uma razão de consistência que tem a intenção de instruir o usuário sobre quaisquer inconsistências ocorridas durante o processo de comparação pareada. $\mathrm{O}$ módulo permite um processo interativo de exploração, no qual o usuário tem a possibilidade de realizar diferentes experimentos com relação à atribuição de pesos (EASTMAN, 1995).

A partir dessa relação ponderada, obteve-se a relação de pesos de cada variável para a BHCC, que segue no Quadro 7.

\begin{tabular}{|cc|}
\hline VARIÁVEIS & PESOS \\
\hline Declividade & $40 \%$ \\
Solos & $23 \%$ \\
Vertentes & $18 \%$ \\
Geologia & $14 \%$ \\
Erosividade & $5 \%$ \\
\hline
\end{tabular}

\section{QUADRO 7 - RELAÇÃO PERCENTUAL DOS PESOS ENTRE AS VARIÁVEIS}

O fator 'declividade' foi o que recebeu o maior peso, já que é, entre os fatores ambientais, o de importância direta com relação aos processos erosivos. Dentro da BHCC, essa condicionante se revela de grande importância, visto que maior parte da área apresenta baixas declividades e estas se ampliam em locais específicos, influenciadas principalmente pela litologia, assim como pelas linhas de fratura e pelas falhas.

O fator 'Solos', apesar de ser o elemento que sofre diretamente com a erosão, relacionando-se assim de forma ativa com esse processo de acordo com suas condições físicas e químicas, teve sua relação ponderada de forma não contundente em função da escala do mapeamento utilizado.

Os fatores 'Vertentes' e 'Geologia' receberam valores intermediários, considerando-se a influência no escoamento superficial do primeiro e a relação da litologia com a composição dos solos, assim como a relação demonstrada entre a litologia da BHCC e os índices de dissecação do relevo e a concentração de linhas de fratura já demonstrados anteriormente nesta pesquisa.

O fator 'Erosividade' foi considerado como o de menor influência, em função da área da BHCC não possuir grande extensão territorial, subentendendo-se assim a pouca variação no regime de chuvas na bacia, assim como por terem sido utilizados dados pluviométricos de uma estação com período de coleta de cinco anos.

De um modo geral, pode-se dizer que os elementos que caracterizam o relevo, ou seja, a 'Declividade' e os 'Tipos Predominantes de Vertentes', assumiram um peso maior na avaliação, totalizando $58 \%$ dos pesos estabelecidos. 


\section{AVALIAÇÃO POR MÚLTIPLOS CRITÉRIOS}

O passo seguinte foi utilizar o módulo MCE (Multi Criteria Evaluation), ou Avaliação por Múltiplos Critérios, que é um método muito usado para avaliar e agregar muitas condicionantes, sendo necessário, porém, antes de efetuar seu uso, reescalonar os dados a serem trabalhados a uma mesma escala de valores (Função Fuzzy), num processo conhecido como padronização (EASTMAN, 1995). O módulo possibilita o cruzamento das variáveis utilizadas considerando-se a relação de pesos proposta entre as variáveis, e gera um mapa com valores que podem variar de ' 0 a 255 '. O resultado obtido foi um mapa com '143' classes, com valores entre ' 10 e 240 '.

O procedimento seguinte foi fazer uma reclassificação da imagem gerada, com o propósito de agrupar os valores em um número menor de classes. A reclassificação foi realizada considerando-se tanto a proximidade das '143' classes entre si como suas respectivas áreas. O resultado obtido foi uma carta com cinco classes, que, de forma crescente, representam os níveis de Fragilidade Potencial da BHCC. (Figura 5)

\section{FIGURA 5 - CARTA DE FRAGILIDADE POTENCIAL DA BHCC}

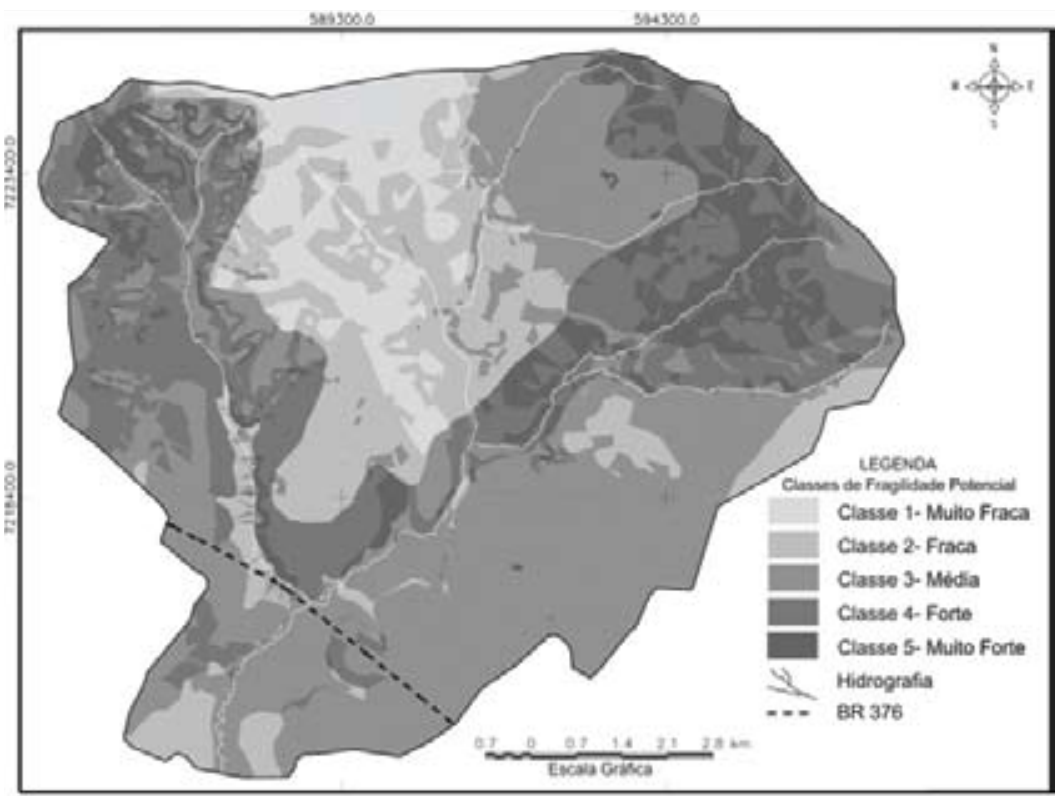

FONTE: MIARA, Marcos A. (Org.) 2006.

\section{ANÁLISE DAS CLASSES DE FRAGILIDADE AMBIENTAL}

Para uma análise a respeito das condições de cada uma das cinco classes finais de fragilidade potencial da BHCC, foi realizada primeiramente uma avaliação quantitativa. Para tanto, foram identificadas quais eram as características de cada classe de fragilidade potencial com relação às variáveis ambientais trabalhadas. Foram calculados os percentuais de área de cada uma das cinco classes, que estão ocupados por cada uma das classes de cada variável ambiental. Esses dados quantitativos foram analisados e ajudaram uma descrição de cada classe de fragilidade potencial da BHCC. Saídas a campo foram realizadas no intuito de visualizar e registrar fotograficamente características físicas das cinco classes, em pontos determinados de cada uma dessas classes.

\section{CLASSE 1 - FRAGILIDADE POTENCIAL MUITO FRACA}

A Classe 1 possui uma área de $8,55 \mathrm{~km}^{2}$, ocorre na área central da bacia e, sendo teoricamente a classe que representa as áreas que os menores potenciais de erosão possui, apresenta as classes definidas como sendo as melhores entre as variáveis na maior parte de sua área. Somente $1,1 \%$ da área encontra-se acima da classe de declividade ' 2 a 6\%', caracterizando-se assim como uma área com baixos declives. Quanto à geologia dessa classe, 99,9\% de sua área encontra-se sobre a Formação Ponta Grossa, caracterizada como a segunda melhor classe dessa variável. Sobre os solos, somente $0,2 \%$ estão fora do tipo Latossolo 'LEa8', que foi definida como a melhor classe. Dos tipos de vertentes predominantes, apenas $0,2 \%$ da área estão fora das 'Vertentes Convexas', que é a classe de segundo menor peso, estando também em $99,6 \%$ na classe de menor potencial erosivo da chuva. (Quadro 8) 
MIARA, M. A.; OKA-FIORI, C. Análise por múltiplos critérios para a definição de níveis de fragilidade ambiental...

\begin{tabular}{|c|c|c|c|c|c|c|c|}
\hline DECLIV. & 0 a $2 \%$ & 2 a $6 \%$ & 6 a $12 \%$ & 12 a $20 \%$ & 20 a $30 \%$ & 30 a $45 \%$ & $\begin{array}{c}\text { MAIOR QUE } \\
45 \%\end{array}$ \\
\hline & 63,9 & 35,1 & 1,0 & 0,1 & 0,0 & 0,0 & 0,0 \\
\hline \multirow[t]{2}{*}{ GEOL } & F. Furnas & $\begin{array}{l}\text { F. Ponta } \\
\text { Grossa }\end{array}$ & F. Serra Geral & $\begin{array}{c}\text { Depósitos Quater- } \\
\text { nários }\end{array}$ & $\begin{array}{c}\text { Falhas } \\
\text { Aproximadas }\end{array}$ & & \\
\hline & 0,1 & 99,9 & 0,0 & 0,0 & 0,0 & & \\
\hline \multirow[t]{2}{*}{ SOLOS } & HG2 & $\mathrm{Ca} 23$ & LEa9 & LEa8 & LEa14 & & \\
\hline & 0,0 & 0,1 & 0,0 & 99,8 & 0,1 & & \\
\hline \multirow[t]{2}{*}{ VERT. } & Retilíneas & Côncavas & Convexas & Planícies & & & \\
\hline & 0,1 & 0,1 & 99,8 & 0,0 & & & \\
\hline \multirow[t]{2}{*}{ EROSIV. } & Classe 1 & Classe 2 & & & & & \\
\hline & 99,6 & 0,4 & & & & & \\
\hline
\end{tabular}

\section{QUADRO 8 - PERCENTUAL DE CADA CLASSE DAS VARIÁVEIS EM ANÁLISE PARA A CLASSE 1 DE FRAGILIDADE POTENCIAL}

\section{CLASSE 2 - FRAGILIDADE POTENCIAL FRACA}

A Classe 2 ocupa uma área de $18,29 \mathrm{~km}^{2}$ e se intercala com a Classe 1 distribuindo-se principalmente pela área central da bacia. Quanto às classes de declividade, há um aumento da classe ' 6 a $12 \%$ ' a se considerar, assim como a classe ' 12 a $20 \%$ ' ocupando $4,4 \%$ de área da Classe 2 . Sobre a variável geologia, acaba a supremacia da classe Formação Ponta Grossa que havia na Classe 1, aparecendo também a Formação
Furnas em $28,7 \%$ dessa classe. Para os solos, nota-se que a maior parte dessa classe é ocupada pelo Latossolo 'LEa8', mas vale destacar a presença da associação Cambissolo e Podzólico 'Ca23' em 15\% da Classe 2, assim como a associação Latossolo Podzólico 'LEa14' em $7,1 \%$ da classe. Sobre as vertentes, houve uma grande distribuição das ocorrências nessa classe se comparada à Classe 1. Para a erosividade da chuva, a 'Classe 1' continua sendo a de expressão. (Quadro 9)

\begin{tabular}{|c|c|c|c|c|c|c|c|}
\hline DECLIV. & 0 a $2 \%$ & 2 a $6 \%$ & 6 a $12 \%$ & 12 a $20 \%$ & 20 a $30 \%$ & 30 a $45 \%$ & $\begin{array}{c}\text { MAIOR QUE } \\
45 \%\end{array}$ \\
\hline \multirow{3}{*}{ GEOL . } & 26,1 & 29,6 & 39,7 & 4,4 & 0,1 & 0,0 & 0,0 \\
\hline & F. Furnas & $\begin{array}{l}\text { F. Ponta } \\
\text { Grossa }\end{array}$ & F. Serra Geral & $\begin{array}{l}\text { Depósitos } \\
\text { Quaternários }\end{array}$ & $\begin{array}{c}\text { Falhas } \\
\text { Aproximadas }\end{array}$ & & \\
\hline & 28,7 & 70,6 & 0,6 & 0,0 & 0,0 & & \\
\hline \multirow[t]{2}{*}{ SOLOS } & HG2 & $\mathrm{Ca} 23$ & LEa9 & LEa8 & LEa14 & & \\
\hline & 0,0 & 15,0 & 7,1 & 70,6 & 7,1 & & \\
\hline \multirow[t]{2}{*}{ VERT. } & Retilíneas & Côncavas & Convexas & Planícies & & & \\
\hline & 10,2 & 26,9 & 46,7 & 16,0 & & & \\
\hline \multirow[t]{2}{*}{ EROSIV. } & Classe 1 & Classe 2 & & & & & \\
\hline & 99,0 & 1,0 & & & & & \\
\hline
\end{tabular}

QUADRO 9 - PERCENTUAL DE CADA CLASSE DAS VARIÁVEIS EM ANÁLISE PARA A CLASSE 2 DE FRAGILIDADE POTENCIAL 


\section{CLASSE 3 - FRAGILIDADE POTENCIAL MÉDIA}

A Classe 3 é a que maior área possui, ocupando $42,01 \mathrm{~km}^{2}$ da BHCC, e ocorre basicamente na parte leste e em especial na parte sudeste da bacia. O que chama a atenção é o fato da declividade nessa classe exercer menor influência, se comparada à Classe 2. Porém, outras variantes despontam como tendo maiores influências, como a geologia, pois $57,1 \%$ da área estão sobre a Formação Furnas. Quanto aos solos, $73,8 \%$ da área são ocupados pelas duas piores classes, a associação Latossolo e Podzólico 'LEa14' e a associação Cambissolo e Podzólico 'Ca23'. Quanto às vertentes, em 57,3\% da área predominam as classes 'Retilíneas' e 'Côncavas' e em $9,8 \%$ as 'Planícies', e num primeiro momento até então, aparece a Classe 2 de erosividade da chuva com valor de $17,5 \%$. (Quadro 10)

\begin{tabular}{|c|c|c|c|c|c|c|c|}
\hline DECLIV. & 0 a $2 \%$ & 2 a $6 \%$ & 6 a $12 \%$ & 12 a $20 \%$ & 20 a $30 \%$ & 30 a $45 \%$ & $\begin{array}{c}\text { MAIOR } \\
\text { QUE 45\% }\end{array}$ \\
\hline & 37,5 & 31,9 & 25,7 & 4,3 & 0,5 & 0,0 & 0,0 \\
\hline \multirow[t]{2}{*}{ GEOL. } & F. Furnas & $\begin{array}{l}\text { F. Ponta } \\
\text { Grossa }\end{array}$ & $\begin{array}{l}\text { F. Serra } \\
\text { Geral }\end{array}$ & $\begin{array}{c}\text { Depósitos } \\
\text { Quaternários }\end{array}$ & $\begin{array}{c}\text { Falhas } \\
\text { Aproximadas }\end{array}$ & & \\
\hline & 57,1 & 34,3 & 2,0 & 6,5 & 0,0 & & \\
\hline \multirow[t]{2}{*}{ SOLOS } & HG2 & $\mathrm{Ca} 23$ & LEa9 & LEa8 & LEa14 & & \\
\hline & 6,5 & 18,1 & 1,6 & 19,7 & 54,1 & & \\
\hline \multirow[t]{2}{*}{ VERT. } & Retilíneas & Côncavas & Convexas & Planícies & & & \\
\hline & 29,7 & 27,6 & 32,9 & 9,8 & & & \\
\hline \multirow[t]{2}{*}{ EROSIV. } & Classe 1 & Classe 2 & & & & & \\
\hline & 82,5 & 17,5 & & & & & \\
\hline
\end{tabular}

\section{QUADRO 10 - PERCENTUAL DE CADA CLASSE DAS VARIÁVEIS EM ANÁLISE PARA A CLASSE 3 DE FRAGILIDADE POTENCIAL}

\section{CLASSE 4 - FRAGILIDADE POTENCIAL FORTE}

A Classe 4 tem uma área de $23,23 \mathrm{~km}^{2}$ e ocorre principalmente no vale do arroio Olarias e seguindo pelo rio Cará-Cará até suas nascentes na porção nordeste da bacia. Nessa classe, há um aumento das médias de declividade. A classe '6 a $12 \%$ ' passa a ocupar $39,1 \%$ e a classe ' 12 a $20 \%$ ' ocupa $13,6 \%$, aparecendo também a classe '20 a 30\%' ocupando $0,7 \%$ da área. A geologia é distribuída entre a Formação Ponta Grossa e a For- mação Furnas. A variável de solos determina a grande alteração dessa classe, pois $99 \%$ dela são formados pelas associações Latossolo e Podzólico 'LEa14' e Cambissolo e Podzólico 'Ca23'. Para as formas predominantes de vertentes, $75 \%$ estão na classe 'Côncavas' e $20,3 \%$ na classe 'Retilíneas', totalizando $95,3 \%$ da área dessa classe com as piores classes dessa variável. Para a erosividade, há um aumento da 'Classe 2', a qual ocupa $27,7 \%$ da área da Classe 4. (Quadro 11)

\begin{tabular}{|c|c|c|c|c|c|c|c|}
\hline DECLIV. & 0 a $2 \%$ & 2 a $6 \%$ & 6 a $12 \%$ & 12 a $20 \%$ & 20 a $30 \%$ & $\begin{array}{l}30 a \\
45 \%\end{array}$ & $\begin{array}{c}\text { MAIOR } \\
\text { QUE 45\% }\end{array}$ \\
\hline \multirow{3}{*}{ GEOL } & 21,5 & 25,1 & 39,1 & 13,6 & 0,7 & 0,0 & 0,0 \\
\hline & F. Furnas & $\begin{array}{l}\text { F. Ponta } \\
\text { Grossa }\end{array}$ & $\begin{array}{c}\text { F. Serra } \\
\text { Geral }\end{array}$ & $\begin{array}{c}\text { Depósitos } \\
\text { Quaternários }\end{array}$ & $\begin{array}{c}\text { Falhas } \\
\text { Aproximadas }\end{array}$ & & \\
\hline & 45,3 & 52,1 & 2,0 & 0,5 & 0,0 & & \\
\hline \multirow[t]{2}{*}{ SOLOS } & HG2 & Ca23 & LEa9 & LEa8 & LEa14 & & \\
\hline & 0,5 & 48,7 & 0,5 & 0,1 & 50,3 & & \\
\hline \multirow[t]{2}{*}{ VERT. } & Retilíneas & Côncavas & Convexas & Planícies & & & \\
\hline & 20,3 & 75,0 & 4,2 & 0,4 & & & \\
\hline \multirow[t]{2}{*}{ EROSIV. } & Classe 1 & Classe 2 & & & & & \\
\hline & 72,3 & 27,7 & & & & & \\
\hline
\end{tabular}
QUADRO 11- PERCENTUAL DE CADA CLASSE DAS VARIÁVEIS EM ANÁLISE PARA A CLASSE 4 DE
FRAGILIDADE POTENCIAL 


\section{CLASSE 5 - FRAGILIDADE POTENCIAL MUITO FORTE}

A Classe 5 possui uma área de $10,07 \mathrm{~km}^{2}$ e distribui-se de forma intercalada com a Classe 4, apresentando um aumento quanto às declividades. A classe ' 6 a $12 \%$ ' passa a ocupar mais da metade da área. Apresenta um aumento da classe ' 12 a $20 \%$ ', que passa para $21,9 \%$, e um acréscimo também da classe '20 a $30 \%$ ', que chega a $15 \%$. As áreas com declives acima de $30 \%$ dentro da bacia se encontram totalmente nessa classe. O substrato geológico que se destaca é a Formação Furnas em $73,7 \%$ da área da classe. Nos solos se mantêm as associações Cambissolo e Podzólico 'Ca23' com 38,6\% e Latossolo Podzólico 'LEa14' com 60,2\% da área, sendo que as duas piores classes dessa variável caracterizam essa classe. Para as formas predominantes de vertentes, há um aumento na classe 'Côncavas' para $85,4 \%$ da área, o que também demonstra a influência dessa variável na Classe 5. A 'Classe 2' de erosividade pela primeira vez assume a maior parte da classe, com $55,4 \%$ da área. (Quadro 12)

\begin{tabular}{|c|c|c|c|c|c|c|c|}
\hline DECLIV. & 0 a $2 \%$ & 2 a $6 \%$ & 6 a $12 \%$ & 12 a $20 \%$ & 20 a $30 \%$ & 30 a $45 \%$ & $\begin{array}{c}\text { MAIOR QUE } \\
45 \%\end{array}$ \\
\hline & 0,7 & 6,8 & 51,7 & 21,9 & 15,0 & 3,2 & 0,7 \\
\hline \multirow[t]{2}{*}{ GEOL . } & F. Furnas & $\begin{array}{l}\text { F. Ponta } \\
\text { Grossa }\end{array}$ & F. Serra Geral & $\begin{array}{c}\text { Depósitos } \\
\text { Quaternários }\end{array}$ & $\begin{array}{c}\text { Falhas } \\
\text { Aproximadas }\end{array}$ & & \\
\hline & 73,7 & 19,6 & 6,1 & 0,4 & 0,1 & & \\
\hline \multirow[t]{2}{*}{ SOLOS } & HG2 & $\mathrm{Ca} 23$ & LEa9 & LEa8 & LEa14 & & \\
\hline & 0,4 & 38,6 & 0,1 & 0,7 & 60,2 & & \\
\hline \multirow[t]{2}{*}{ VERT. } & Retilíneas & Côncavas & Convexas & Planícies & & & \\
\hline & 11,6 & 85,4 & 2,4 & 0,6 & & & \\
\hline \multirow[t]{2}{*}{ EROSIV. } & Classe 1 & Classe 2 & & & & & \\
\hline & 44,6 & 55,4 & & & & & \\
\hline
\end{tabular}

QUADRO 12 - PERCENTUAL DE CADA CLASSE DAS VARIÁVEIS EM ANÁLISE PARA A CLASSE 5 DE FRAGILIDADE POTENCIAL

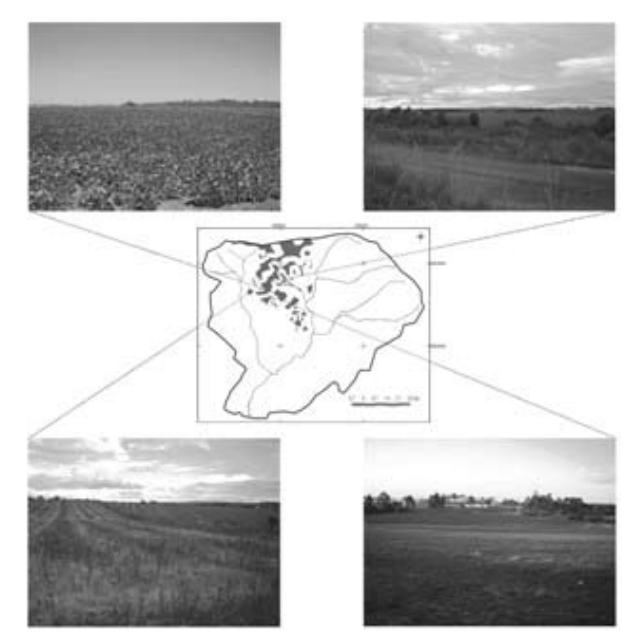

FONTE: MIARA, Marcos A. (Org.), 2006

FIGURA 6 - CLASSE 1 ESPACIALIZAÇÃO E REGISTROS FOTOGRÁFICOS

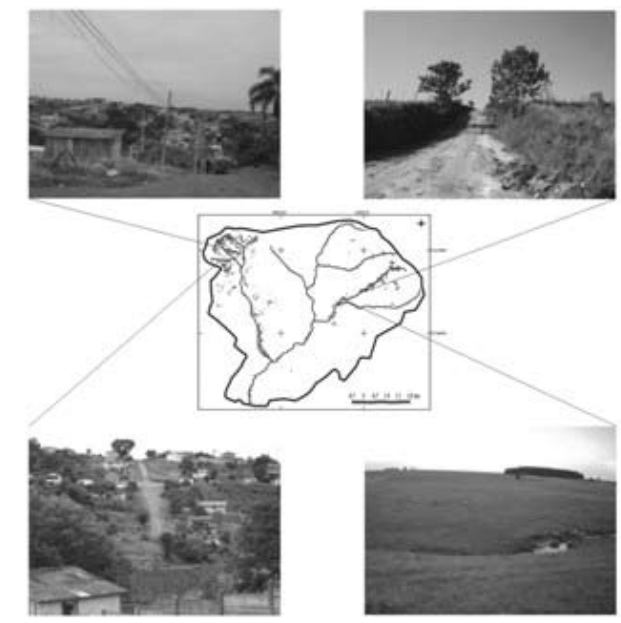

FONTE: MIARA, Marcos A. (Org.), 2006

FIGURA 7: CLASSE 5 ESPACIALIZAÇÃO E REGISTROS
FOTOGRÁFICOS 
MIARA, M. A.; OKA-FIORI, C. Análise por múltiplos critérios para a definição de níveis de fragilidade ambiental...

As Figuras 6 e 7 representam respectivamente as Classes 1 e 5 de Fragilidade Potencial da BHCC. Nelas estão representadas a distribuição espacial de ambas as classes e os registros fotográficos para demonstração de determinadas características das mesmas.

\section{CONSIDERAÇÕES FINAIS}

Conforme as análises realizadas para identificar as características físicas de cada classe de Fragilidade Potencial da BHCC, assim como pelas saídas a campo realizadas a fim de verificações dos resultados (demonstrados nos Quadros 8 a 12 e nas Figuras 6 e 7 ), a pesquisa se conclui considerando que o método proposto atingiu seus objetivos. Isso se verificou pelas cinco classes de Fragilidade Potencial que classificaram áreas com características distintas quanto às variáveis analisadas, compondo assim a identificação de locais que apresentam combinações específicas entre as variáveis físicas.

O método AHP (Analytic Hierarchy Process) se mostrou eficiente por aplicar uma comparação par a par entre as variáveis, considerando assim as diferentes influências exercidas por cada variável física aos processos erosivos dentro da bacia. Para análises de cunho ambiental, o método apresenta desempenho favorável por essa possibilidade de congregar dentro de uma única avaliação um grande número de variáveis.

A relação de pesos proposta entre as variáveis, após uma série de relações testadas e analisadas, se mostrou satisfatória, pois demonstrou correlações com a realidade estudada na bacia. Há que se considerar ainda que o resultado não defina quais formas de uso podem ser aplicadas, e sim quais são as áreas com maior ou menor potencial de degradação por usos quaisquer, fazendo com que o resultado sirva como subsídio aos processos de tomada de decisão sobre aplicação de usos na bacia hidrográfica do rio Cará-Cará.

\section{REFERÊNCIAS}

AGUIAR NETO, Alencar. Folha Ponta Grossa (SG-22-XC-II-2), escala 1:50.000. Comissão da Carta Geológica do Paraná - Projeto Leste do Paraná, Convênio CPRM - DNP, - BADEP - UFPR, 1977.

BERTONI, José; LOMBARDI NETO, Francisco. Conservação do solo. São Paulo: Ícone, 1990.
BOIKO, Josemara Daron. Mapeamento geomorfológico e fragilidade ambiental da bacia hidrográfica do rio Curralinho - Região Metropolitana de Curitiba - PR. Dissertação de Mestrado. Curitiba, Universidade Federal do Paraná, 2004.

BOIKO, J. D.; SANTOS, L. J. C. Caracterização geomorfológica preliminar da bacia do rio Curralinho, Região Metropolitana de Curitiba - PR. In: V Simpósio Nacional de Geomorfologia e I Encontro Sul-Americano de Geomorfologia. UFSM - RS, 2004. Anais...

CREPANI, Edison et al. Sensoriamento remoto e geoprocessamento aplicados ao zoneamento ecológicoeconômico e ao ordenamento territorial. Ministério da Ciência e Tecnologia - Instituto Nacional de Pesquisas Espaciais/INPE. São José dos Campos, 2001.

DSG. Carta Topográfica - Folha Ponta Grossa SG. 22-X-C-II / 2 (MI - 2840/2), em escala 1:50.000, com Sistema de Projeção UTM, Datum vertical de Imbituba, Santa Catarina, e Datum horizontal de Córrego Alegre, Minas Gerais, 1980.

EASTMAN, J. R. Idrisi for Windows users guide. Clark University, Worcester, 1995.

GODOY, L. C. Mapa Geológico do Município de Ponta Grossa. MINEROPAR (Minerais do Paraná S.A.) e Prefeitura Municipal de Ponta Grossa. Escala 1:250.000, 200?.

HIGA, A. R. (Coord.). SIFLOR. Curitiba, 2003. 1 CD-ROM.

INPE - Instituto Nacional de Pesquisas Espaciais, Spring v. 4.1.1, 2005.

KLEIN, Roberto Miguel; HATSCHBACH, Gerdt. Fitofisionomia e notas complementares sobre o mapa fitogeográfico de Quero-Quero (Paraná). Boletim Paranaense de Geociências, Curitiba, v. 28-29, p. 159-188, 1971.

LARACH, Jorge Olmos Iturri et al. (Coord.). Levantamento de Reconhecimento dos Solos do Estado do Paraná. Curitiba, EMBRAPA - SNLCS. Boletim Técnico, 57 - TOMO $1,1984^{1}$.

LARACH, Jorge Olmos Iturri et al. (Coord.). Levantamento de Reconhecimento dos Solos do Estado do Paraná. Curitiba, EMBRAPA - SNLCS. Boletim Técnico, 57 - TOMO $2,1984^{2}$.

LEITE, Pedro Furtado; KLEIN, Roberto Miguel. Vegetação. In: IBGE. Geografia do Brasil. Rio de Janeiro: 1990. v. 2: Região Sul. p. 113-150.

LOMBARDI NETO, F.; MOLDENHAUER, W. C. Erosividade da chuva: sua distribuição e relação com perdas de solo em Campinas, SP. In: ENCONTRO NACIONAL DE PESQUISA SOBRE CONSERVAÇÃO DO SOLO, 3., Recife, 1980. Anais... fl.13.

MINEROPAR. Atlas Geológico do Estado do Paraná. Curitiba, 2001. 
MIARA, M. A.; OKA-FIORI, C. Análise por múltiplos critérios para a definição de níveis de fragilidade ambiental...

MORO, Rosemeri Segecin. A vegetação dos Campos Gerais da escarpa devoniana. In: DITZEL, C. H. M.; SAHR, C. L. L. (Org.). Espaço e cultura: Ponta Grossa e os Campos Gerais, Ponta Grossa: Editora UEPG, 2001.

MORO, Rosemeri Segecin; KACZMARECH Renoaldo. Caracterização Geral da Vegetação da Bacia do Arroio Olarias. In:ANDRADE FILHO, A. G. .(Coord.). Planejamento Ambiental da Bacia do Arroio de Olarias. Universidade Estadual de Ponta Grosa, Núcleo de Estudos em Meio Ambiente - NUCLEAM Prefeitura Municipal de Ponta Grossa, 2001.

PENTEADO, M. M. Fundamentos de Geomorfologia. IBGE, Secretaria de Planejamento da Presidência da República. 3. ed. Rio de Janeiro: Bertran, 1980.

RODRIGUES, C. S. Análise empírico-experimental da fragilidade relevo-solo no cristalino do planalto paulistano: sub-bacia do reservatório Billings. São Paulo, 1998. Tese (Doutorado em Geografia Física) - Faculdade de Filosofia e Ciências Humanas, Universidade de São Paulo.

ROSS, Jurandyr L. Sanches. Geomorfologia Ambiente e Planejamento. São Paulo: Contexto, 1990.
Análise empírica da fragilidade dos ambientes naturais e antropizados. Revista do Departamento de Geografia, USP - Faculdade de Filosofia, Letras e Ciências Humanas, n. 8, 1994.

. Análises e sínteses na abordagem geográfica da pesquisa para o planejamento ambiental. Revista do Departamento de Geografia, USP - Faculdade de Filosofia, Letras e Ciências Humanas, . 9, 1995.

SOARES, Paulo César; FIORI, Alberto Pio. Lógica e sistemática na análise e interpretação de fotografias aéreas em geologia. Notícias Geomorfológicas, Campinas, v. 16, n. 32, p. 71, 1976.

ZAMBON, Kátia Lívia, CARNEIRO, Adriano Alber de França M., SILVA, Antônio Nélson Rodrigues da et al. Análise de decisão multicritério na localização de usinas termoelétricas utilizando SIG. Pesqui. Oper. [online]. May/Aug. 2005, v. 25, n. 2, p.183-199. Disponível em: <http://www.scielo.br/scielo. php?script=sci_arttext\&pid=S010174382005000200002\&Ing =en\&nrm=iso> Acesso em: 7/12/2005. 